\title{
ANALYSIS OF RESULTS OF MONITORING AND PREDICTION OF QUALITY DEVELOPMENT OF BALLASTED AND BALLASTLESS TRACK SUPERSTRUCTURE AND ITS TRANSITION AREAS
}

Securing durability of parameter quality of track alignment design and track geometry is a goal of each railway infrastructure manager. To accomplish this goal, various methods and procedures are applied, but they are all based on regular diagnostics, analysis of its results according to valid legislation and design and implementation of respective maintenance and repair works. The technological and economic optimization of planning and implementation of maintenance and repair works, based on prediction of quality development of railway track, is conditioned by precisely implemented and evaluated monitoring. In relation to these facts, the first part of the paper brings an overview of the problem of monitoring the ballastless structure and its transition areas around portals of the Turecky vrch tunnel by methods of complex diagnostics and quality evaluation of the structure including prediction of the structural quality development. The second part of the paper deals with the analysis of the detected errors of the ballastless track with specific focus on transition areas and on the ballasted track. It also summarizes the possibilities of elimination of these errors in building further sections with ballastless track. Modernization of these sections within modernization of ZSR infrastructure is a topical problem.

Keywords: Railway track, railway superstructure, diagnostics, track geometry, measuring trolley KRAB ${ }^{T M}$-Light.

\section{Monitoring of the experimental section}

The railway track monitoring determines the state of constructions and facilities of railway infrastructure, state of particular structural parts and their functioning, parameters and wear, with regard to tolerances, health, fire and environmental safety, clearances along the track and walking and handling clearance. The operational capability of railway track is verified by inspections and measurements of constructions and facilities of railway infrastructure in prescribed intervals [1].

The diagnostics of the rail route is focused on:

- track skeleton structure

- parameters of the track geometry of the track and turnout,

- structural elements of the track and turnout,

- subgrade structure,

- entire structure,

- rail bed,

- substructure,

- foundation,

- clearances along a line,

- catenary (measurement of the contact wire geometry),

- bridges and tunnels
- inspections,

- photogrammetric measurements,

- clearances along the track and supporting strength,

- moving rail vehicles and detection of their defects (flat wheels, etc.),

buildings and utilities.

The paper presents the results of diagnostics of track geometry, carried out by the Department of Railway Engineering and Track Management, Faculty of Civil Engineering, University of Zilina since 2012. The diagnostics is performed in the experimental section near the portals of the Turecky vrch tunnel, as shown by Fig. 1. The objective of the diagnostics is to regularly determine and assess the quality of given parameters, monitor continuously the quality development and predict its future development due to optimization of design and implementation of maintenance and repair works.

The experimental section in the area of portals of the Turecky vrch tunnel, its parameters, measuring devices and diagnostics methods, its assessment and partial results were in detail specified in [2] and this monitoring will continue in the future.

The monitored section has a unique superstructure in Slovak Republic: ballasted and ballastless superstructure. Between these two structures there is a transition area, which is the most

\footnotetext{
* Libor Izvolt, Janka Sestakova, Michal Smalo

Department of Railway Engineering and Track Management, Faculty of Civil Engineering, University of Zilina, Slovakia

E-mail: libor.izvolt@fstav.uniza.sk
} 
demanding structure here from the point of view of quality maintenance. The transition area superstructure is formed by railbed in a concrete trough with a variable bottom thickness. From the point of view of diagnostics implementation, the monitored section is divided into subsections:

- section 1.1 (rail no. 1, south portal of Turecky vrch tunnel) and 2.1 (rail no. 2, south portal; both sections are $175 \mathrm{~m}$ long; $\mathrm{km} 102.360000-\mathrm{km} 102.535000)$ :

- $\quad \mathrm{km} 102.360000-\mathrm{km} 102.460500$ ballasted superstructure (conventional railway superstructure),

- $\quad \mathrm{km} 102.460500$ - km 102.480500 transition area,

- $\quad \mathrm{km} 102.480500$ - km 102.535000 ballastless track (unconventional superstructure).

- section 1.2 (rail no. 1, north portal of Turecky vrch tunnel) and 2.2 (rail no. 2, north portal); both portals are $640 \mathrm{~m}$ long; km 104.200000 - km 104.840000$)$ :

- $\quad \mathrm{km} 104.200000$ - km 104.720500 ballastless track,

- $\quad \mathrm{km} 104.720500$ - km 102.740500 transition area,

- $\quad \mathrm{km} 104.740 \quad 500 \quad$ - $\mathrm{km} \quad 104.840 \quad 000$ ballasted superstructure.

The comprehensive diagnostics of the experimental section is carried out by the measuring trolley $K R A B^{T M}$-Light using a complex continuous method. As a complementary method, partial point diagnostics by a manual gauge bar was applied here. The implementation and results of the experimental section diagnostics by this method are closely characterized in $[4,5$ and $6]$.

The monitoring method used by the measuring device $K R A B^{T M}$ - Light is contact while the measured data is recorded in the on-board computer.
After transfer to the computer, on the basis of defined parameter limits of track geometry, for each part of the experimental section there were created: the graph of measured parameters of track geometry, table of local errors with the list of exceeded tolerances and the table of section evaluation which is based on standard deviations of variables $(S D V)$, quality marks $(Q M)$ and quality numbers $(Q N)$.

The evaluation of a section by the number of quality, calculated according to the equation:

$$
Q N=\sqrt{\begin{array}{l}
0,57 \cdot S D V_{R K}^{2}+1,6 \cdot S D V_{S P, S L}^{2}+ \\
+1,6 \cdot S D V_{P K}^{2}+1,6 \cdot S D V_{V P . V L}^{2}
\end{array}}
$$

where:

$S D V_{R K}$ - Standard tolerance of variable of track gauge,

$S D V_{S P, S L}$ - Standard tolerance of variable of direction of the track, $S D V_{P K}$ - Standard tolerance of variable of track superelevation, $S D V_{V P, V L}$ - Standard tolerance of variable of rail top level.

where (mm) $S D V=\sqrt{\frac{1}{n-1} \sum_{i=1}^{n} x_{i}^{2}}$

expresses irregular course of the track geometry parameter in the section evaluated, where:

$n$ - number of points measured each $0.25 \mathrm{~m}$,

$i$ - marking measuring point,

$x$ - dynamic component of the relevant quantity of track geometry (tolerance from the center line in the wavelength range $1 \mathrm{~m}$ to $25 \mathrm{~m})$.

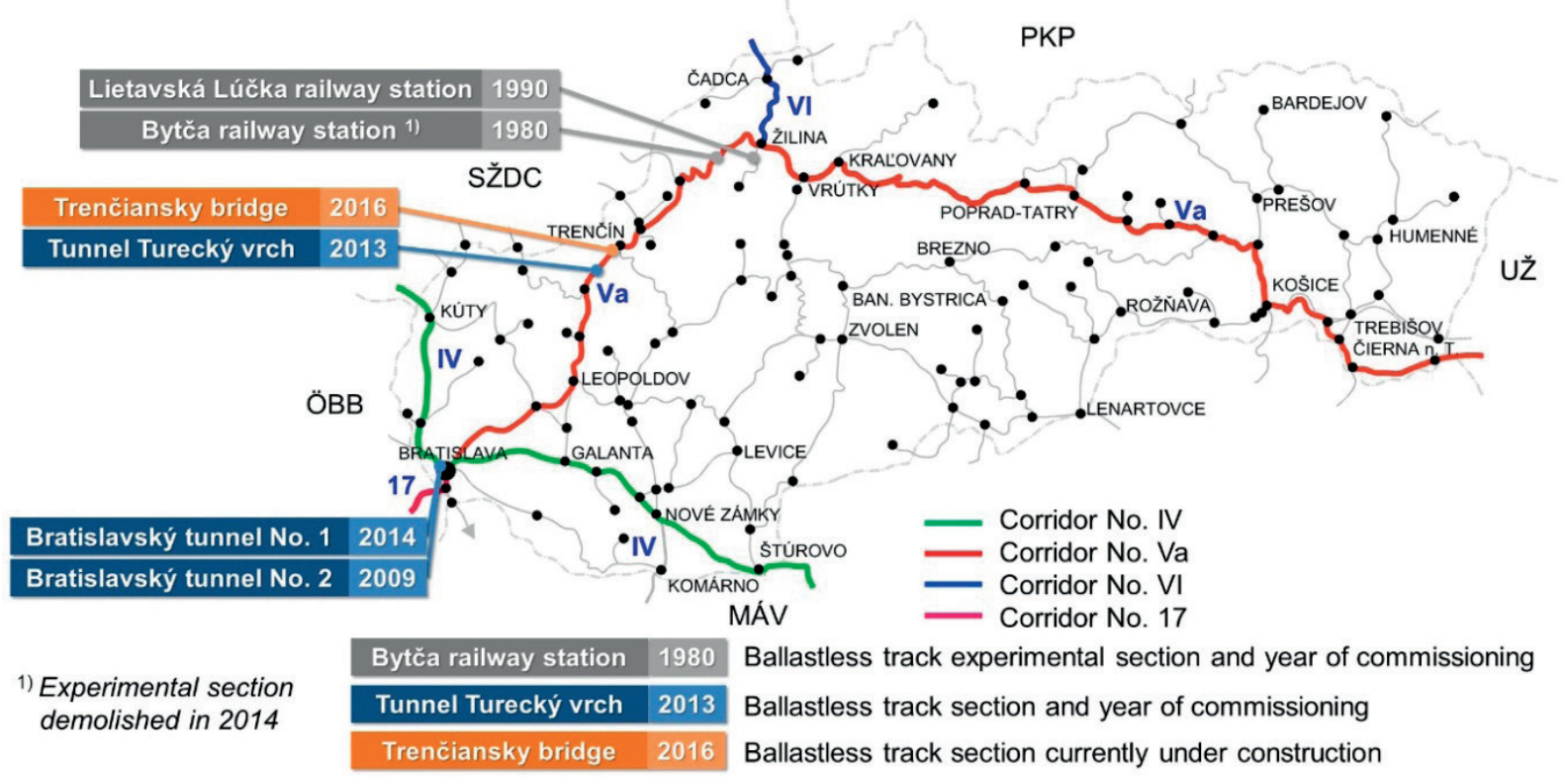

Fig. 1 Ballastless track sections in the railway infrastrucure of the Slovak Republic [3] 
The evaluation of section according to quality marks shall be carried out according to the equation:

$Q M=\frac{\operatorname{In} \frac{S D V}{b}}{m}$

where $b$ and $m$ are numerical constants determined on the basis of the $S D V$ statistics of relevant parameter and speed zone.

The evaluation using the list of local errors and the section evaluation respect conditions stated in [7 and 8], for tracks with track speed from $120 \mathrm{~km} \cdot \mathrm{h}^{-1}$ to $160 \mathrm{~km} \cdot \mathrm{h}^{-1}$ included (i. e. for speed zone No. 4 /RP 4/). The provisions of the currently valid document [9] have so far not been included in the respective legislation by the railway infrastructure manager. The measured parameters were evaluated using software according to maximum input tolerances for acceptance of works with the use of new material (MSO), or according to operational tolerances and maximum operational tolerances for RP4 (PO1 to PO7).

The particular measurements in the experimental section were carried out as follows:

- input measurement before putting the structure to operation (MSO), on 10. 7. 2012, 11. 7. 2012, 2. 10. 2012 and 3. 10. 2012,

- first operational measurement (PO1) on 9. 4. 2013, 10. 4. 2013, 21. 4. 2013 and 22. 4. 2013,

- second operational measurement (PO2) on 8. 10. 2013, 9. 10. 2013, 21. 10. 2013 and 22. 10. 2013,

- third operational measurement (PO3) on 25. 5. 2014 and 28. 5. 2014,
- fourth operational measurement (PO4) on 29. 10. 2014,

- fifth operational measurement (PO5) on 25. 3. 2015 and 17. 4. 2015 ,

- sixth operational measurement (PO6) on 14. 10. 2015 and 15. 10. 2015,

- seventh operational measurement (PO7) on 22. 03. 2016 and 23. 03. 2016.

\section{Analysis of results of the experimental section monitoring}

The quality of the track geometry of each evaluated section is presented using:

- graphs of measured parameters of track geometry,

- tables of local errors with an overview of exceeded maximum values (standard tolerances) of measured parameters and

- tables of section evaluation which show:

- standard tolerances (SDV) and quality marks (QM) of particular geometric quantities - alignment of the track (SK), track gauge (RK), superelevation (PK) and rail top level (VK),

- overall quality mark (OQM) which serves for assessment of track geometry in the evaluated section as a whole,

- tamping mark (TM), which helps decide whether to deploy a tamping machine. Unlike OQM, it does not consider gauge tolerances (RK). (They are not maintained by tamping machines).

- quality number $(Q N)$.

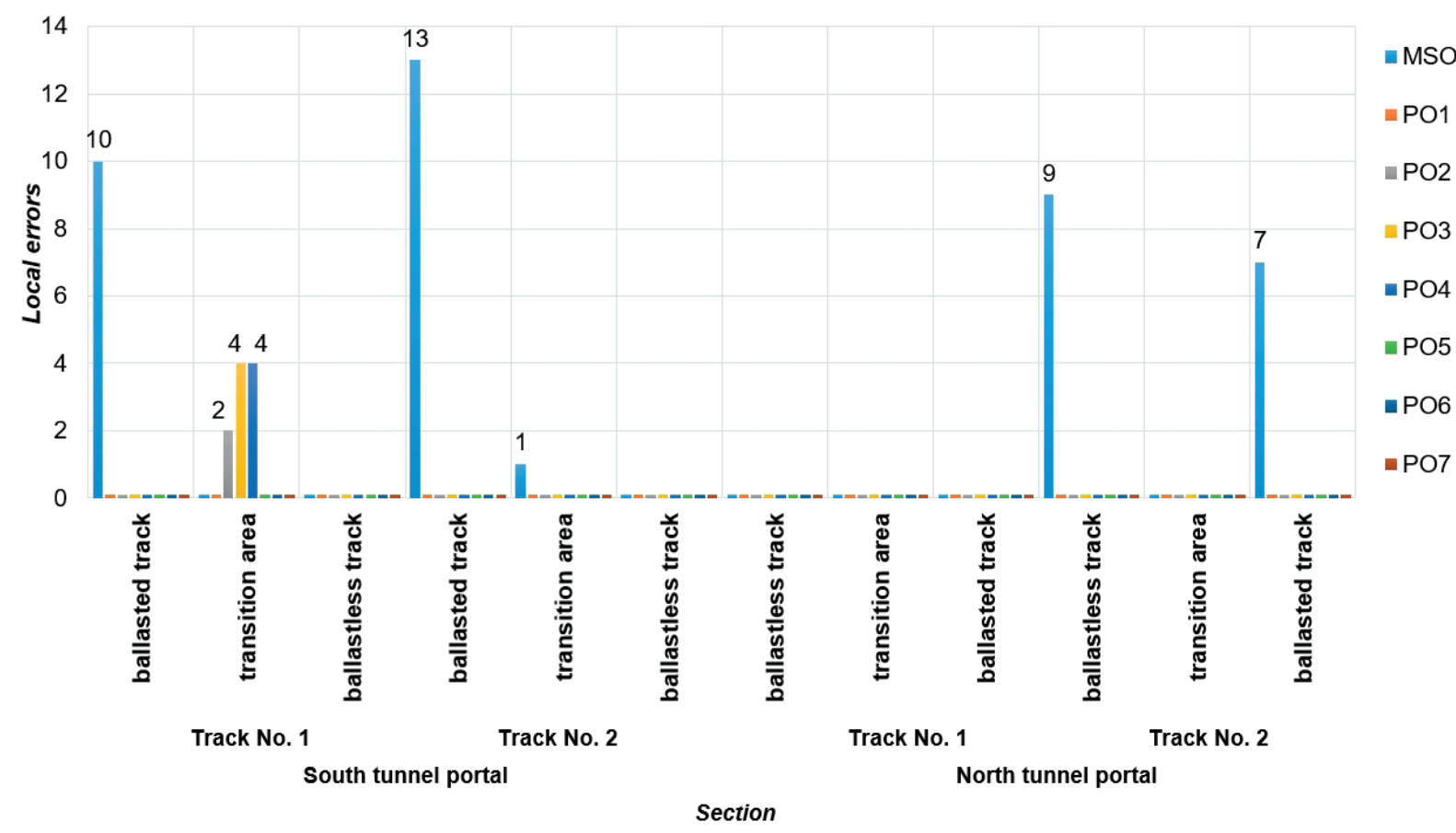

Fig. 2 Incidence of local errors in the monitored section- measurements carried out using measuring trolley KRAB ${ }^{T M}$-Light 
The overview of quality development of the track geometry of the monitored section is shown in Figs. 2 - 7. The incidence of local errors of measured parameters is stated separately for ballasted track sections, transition areas and for ballastless track sections (Fig. 2).

\subsection{Local errors}

The experimental section monitoring has been carried out since July 2012, with six-month periodicity. The input measurement (MSO) was carried out 2 days before putting the track in operation. Within the input measurement, 40 local errors were recorded, out of them 30 in sections with ballasted track, 9 in sections with ballastless track and 1 local error was diagnosed in the transition area of the section 2.1. After this measurement, the supplier carried out the repair of track geometry and microgeometry of rail heads by grinding in the transition areas and in the sections with gravel superstructure (unfortunatelly, the supplier did not provide the details of repair works). The operational diagnostics has been applied seven times (PO1 to PO7).

In the second operational measurement (PO2), the local errors of the rail top level of the right rail $(V P)$ and the top level of left rail $(V L)$ were for the first time recorded in the transition area of the section 1.1, confirmed by the track geometry car of ZSR (Zeleznice Slovenskej republiky - the Railways of the
Slovak Republic). In the following measurements - PO3 and PO4 - further quality degradation of the section 1.1 was diagnosed, confirmed by the increased number of local errors (Fig. 2) as well as worsening value (increase) of the overall number of quality (Fig. 7). In November 2014, the railway infrastructure manager carried out repair interventions in the transition areas of the sections 1.1 and 2.1. In this way the diagnosed local errors were removed. The complex continuous diagnostics, carried out by the measuring trolley $K R A B^{T M}$ - Light, and monitoring by the railway infrastructure manager applying the levelling method from December 2014 to August 2015 in the sections 1.1 and 1.2 confirm further lowering of the track. Their values cannot at present be considered local errors as the operational tolerances were not exceeded. However, due to further degradation of particular parameters of the sections in question, incidence of local errors is expected in the near future. The sections 1.2 and 2.2 in the transition areas do not show any errors in values. The quality development in the measurements carried out so far do not indicate any probability of their incidence in further measurements [5, 6 and 10].

\subsection{Section evaluation}

The quality marks of the alignment of the right rail (after calculation also of the left one) $Q M_{S K}$ (Fig. 3) were within MSO, $\mathrm{PO} 1, \mathrm{PO} 2$ and $\mathrm{PO} 3$ measurements placed in the interval $2<Q M \leq$

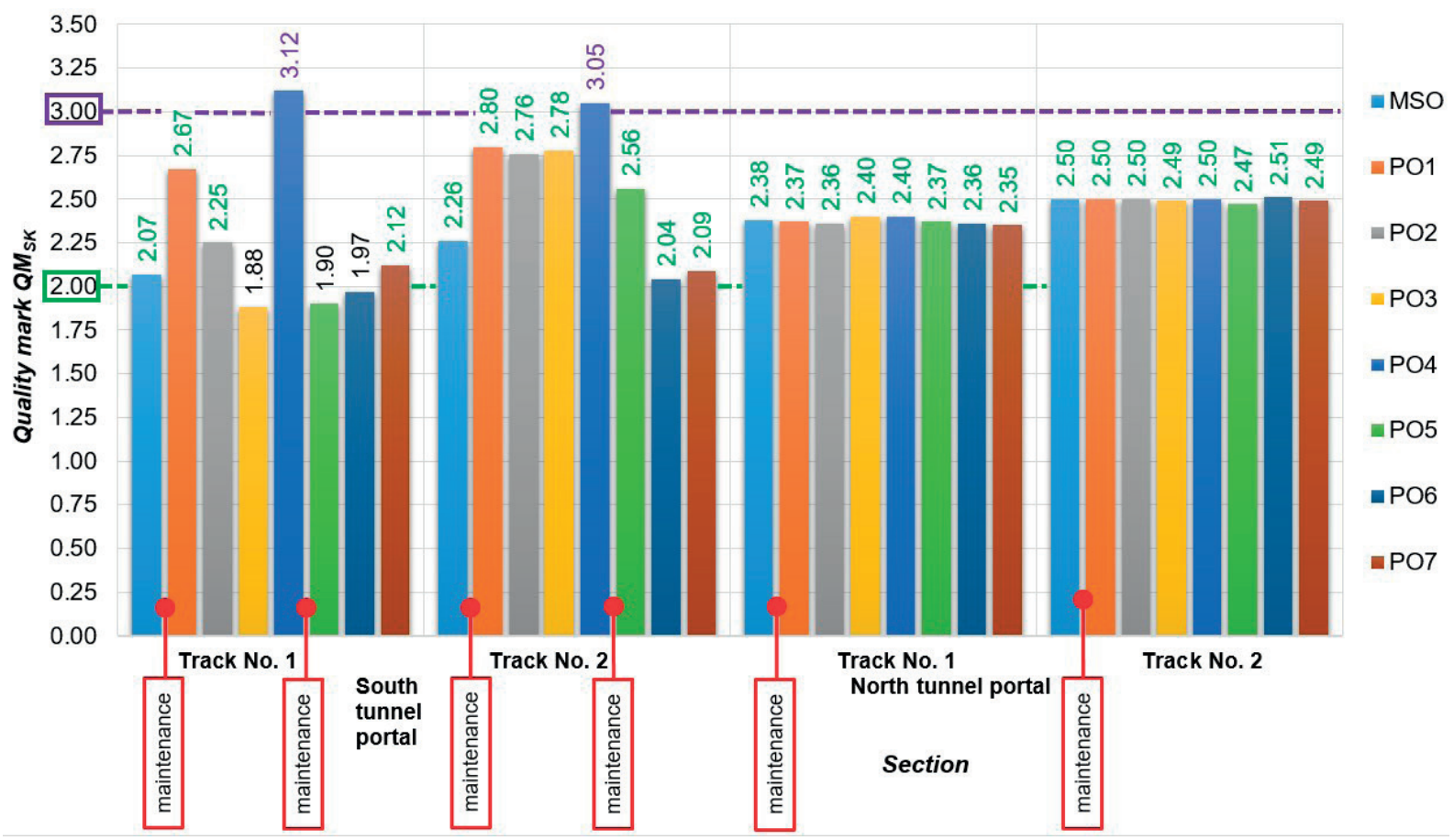

Fig. 3 Quality marks of the geometric quantity alignment of the right rail in respective monitored sections - measurement carried out by measuring trolley KRAB ${ }^{T M}$-Light 


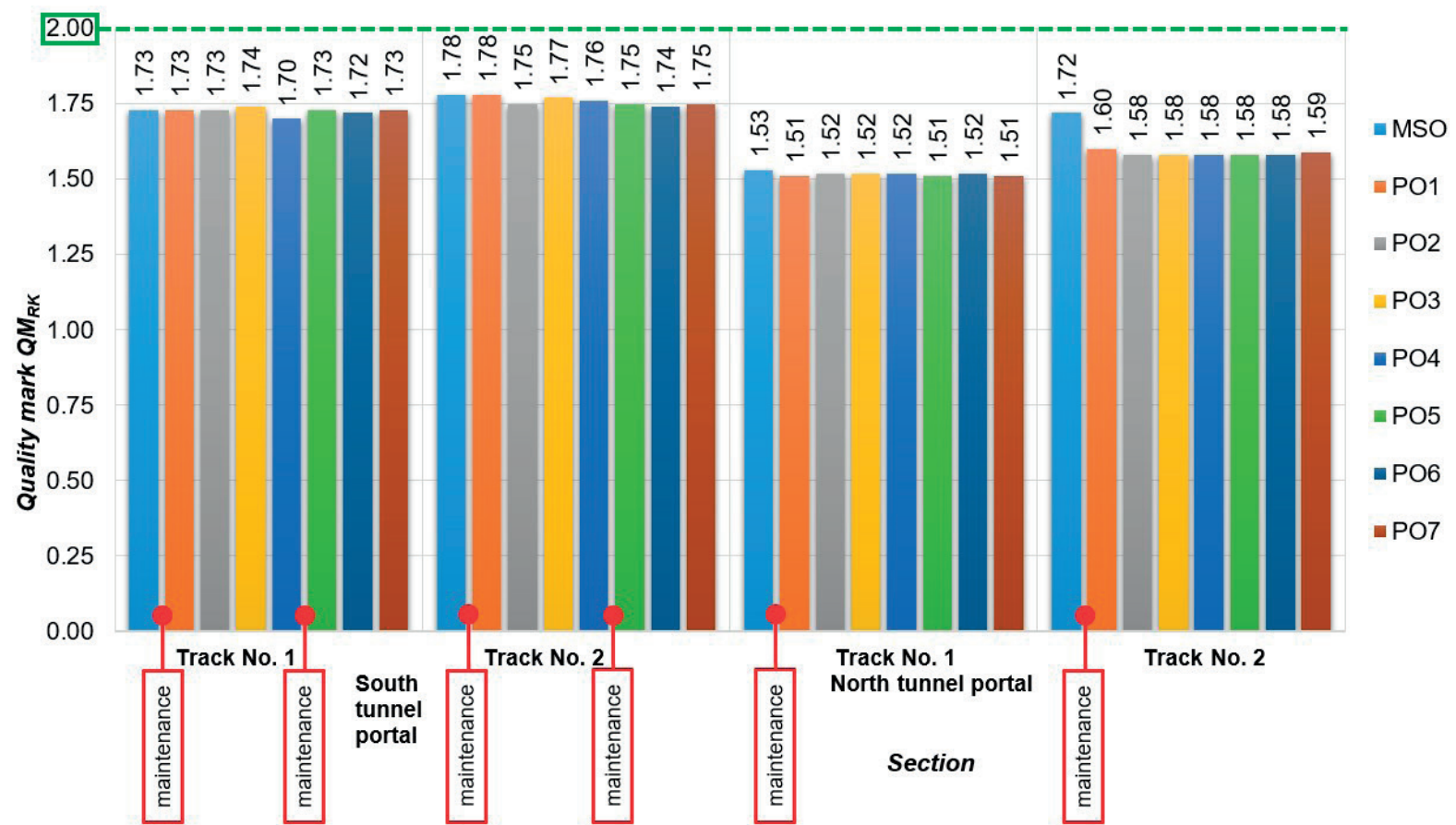

Fig. 4 Quality marks of the geometric quantity rail gauge tolerance in respective monitored sections - measurements carried out by measuring trolley KRAB ${ }^{T M}$ - Light

3 (recommendation: to design the repair of track geometry in the maintenance work plan) in all the monitored sections. The quality marks in the interval $3<Q M \leq 4$ (recommendation: to carry out the repair of the track geometry until the nearest inspection) were reached in the sections 1.1 and 2.1 within PO4 measurement. After repair interventions before PO5 measurement, the values of quality marks improved (decreased) to the interval $0<Q M$ $\leq 2$ (the state of the track geometry in the evaluated section is

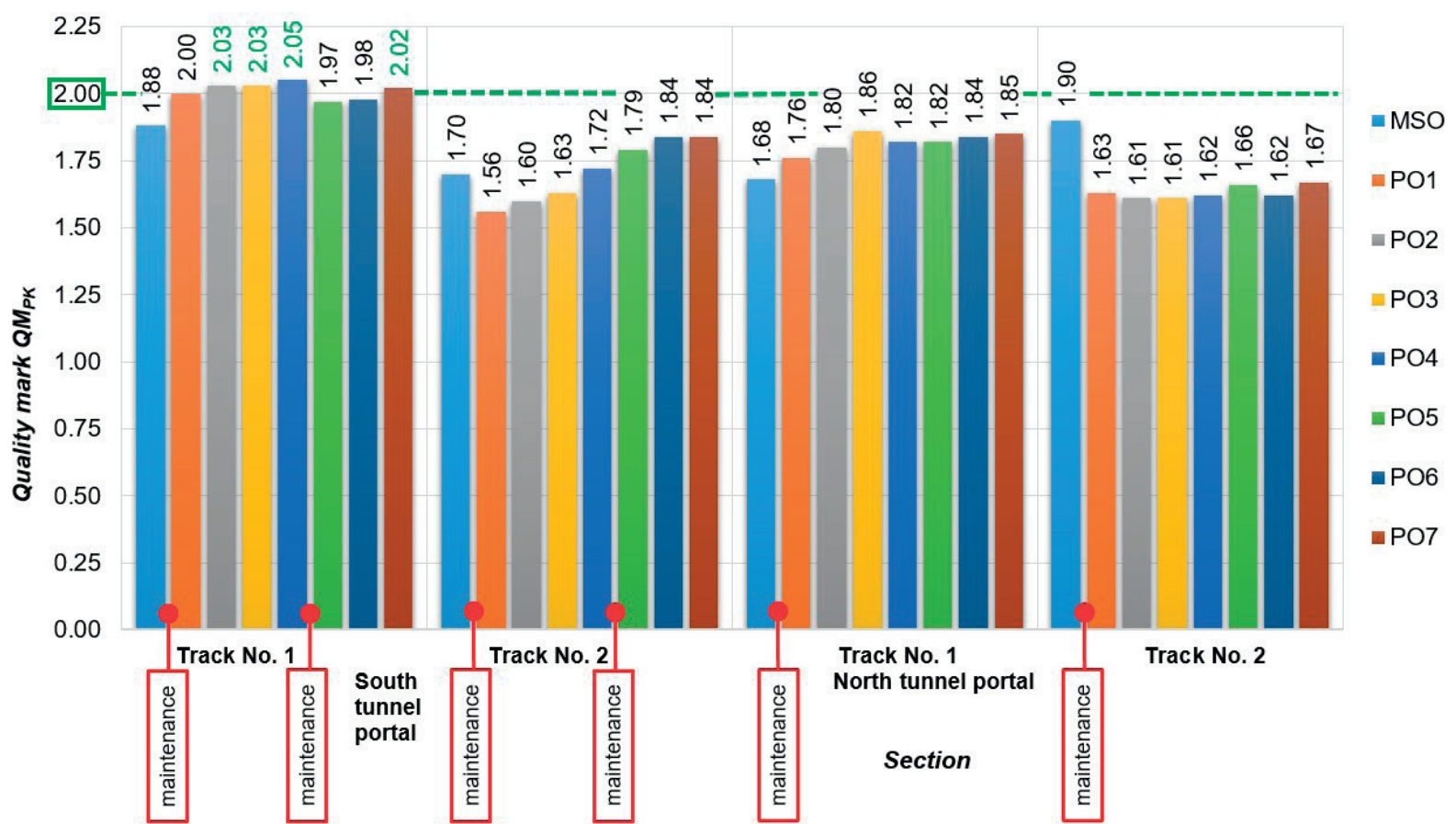

Fig. 5 Quality marks of the geometric quantity rail superelevation in respective monitored sections - measurements carried out by measuring trolley $K R A B^{T M}-$ Light 


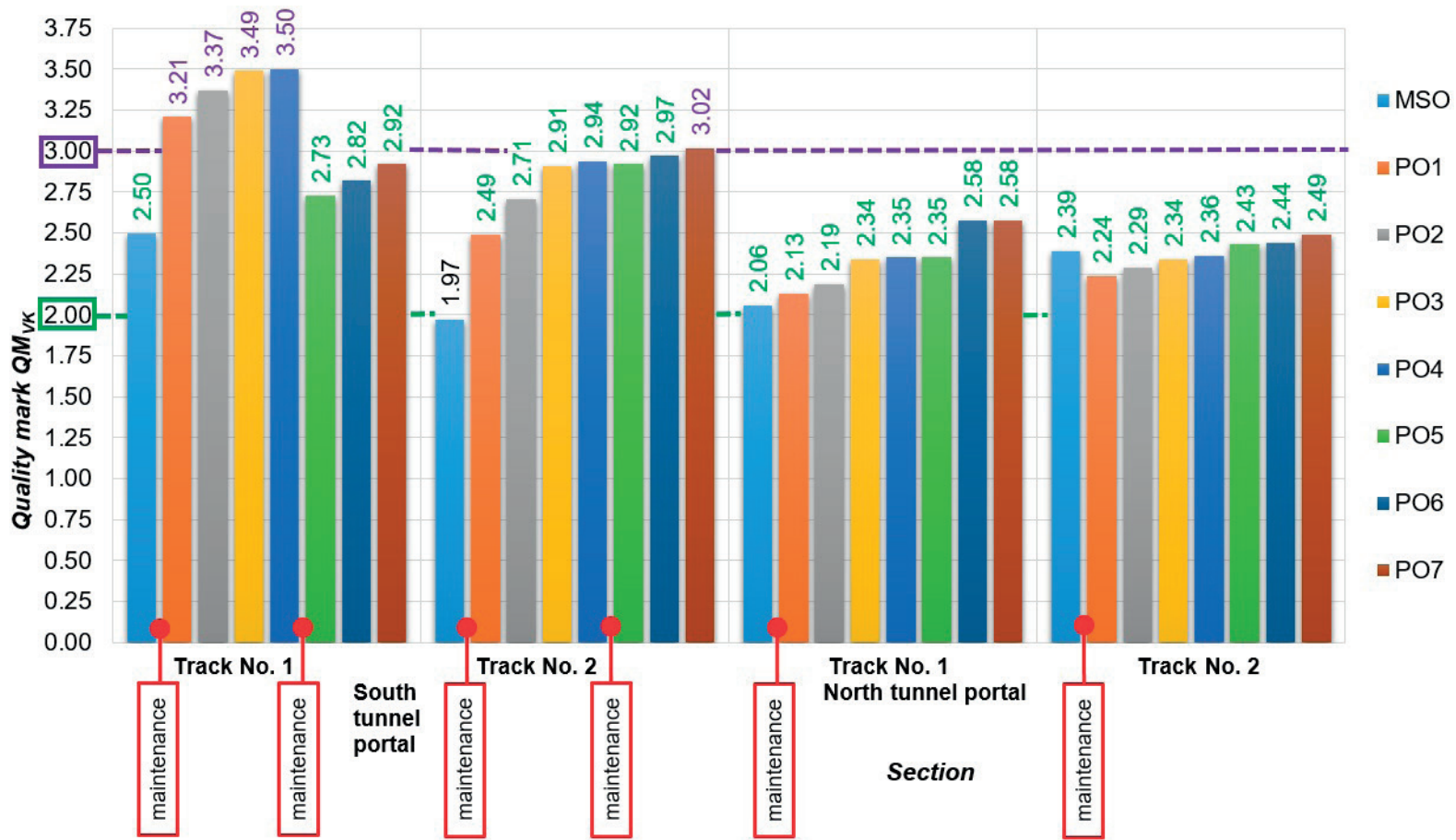

Fig. 6 Quality marks of geometric quantity rail top level of the right rail in respective monitored sections - measurement carried out by the measuring trolley $K R A B^{T M}$ - Light

satisfactory) in the section 1.1 or to $2<Q M \leq 3$ in the section 2.1. In PO7 measurement, slight deterioration of $Q M_{S K}$ in the section 1.1 was found out placing it to the interval $2<Q M \leq 3$.

The quality marks of rail gauge tolerance $Q M_{R K}$ in all the sections and measurements are in the interval of values $0<Q M \leq$ 2 , which indicates that the state of track geometry is satisfactory (Fig. 4). Higher values of quality marks $Q M_{R K}$ in the sections 1.1 and 2.1 result from higher share of ballasted track sections compared to the sections 1.2 and 2.2 with prevailing better quality ballastless track (also securing higher durability of rail position). The values of $Q M_{R K}$ obtained by monitoring carried out during operation (measurements PO1 to PO7) present the rail gauge as a parameter with permanently satisfying quality development.

The quality marks of superelevation $Q M_{P K}$ are in the interval of values $0<Q M \leq 2$ in all the sections and $2<Q M \leq 3$ in measurements $\mathrm{PO}$, $\mathrm{PO} 3, \mathrm{PO} 4$ and $\mathrm{PO} 7$ in the section 1.1. After repair interventions (after $\mathrm{PO} 4$ measurement) the values moved into the interval $0<Q M \leq 2$. The trend of quality increase in this section proven by measurements PO5 and PO6, is indicated as stopped by measurement PO7: the quality mark $Q M_{P K}$ is in the interval $2<Q M \leq 3$ (Fig. 5).

The quality mark with the worst development according to the measurements carried out so far seems to be the quality mark of the top level of the right (after calculation also of the left) rail $Q M_{V K}$ (Fig. 6).

The errors of the parameter of the top level of rails are the most frequently occurring defects, which is also confirmed by evaluation of measurements by the track recording car of ZSR. With the exception of measurement MSO in the section 2.1, in all the measurements of monitored sections the determined values were $2<Q M \leq 3$ and in the measurements $\mathrm{PO} 1, \mathrm{PO}$, $\mathrm{PO} 3$ and PO4 in the section 1.1 the values were $3<Q M<4$ which indicates the necessity to carry out the repair of track geometry until the nearest inspection. By the repair intervention carried out in sections 1.1 and 2.1, before measurement PO5, the values of $Q M_{V K}$ decreased. The measurements PO5 and PO6 placed these values into the interval $2<Q M \leq 3$. In the measurement PO7 $Q M_{V K}$ reached values in the interval $3<Q M<4$, in the section 2.1. The tendency of quality mark deterioration in the section 1.1 predicts the determination of $Q M_{V K}$ value within the interval $2<$ $Q M \leq 3$ in the near future.

Within PO1, PO2, PO3 and PO4 measurements, further continuous quality deterioration of sections 1.1. and 2.1 was determined, as indicated by the overall quality number. The repair interventions, carried out in November 2014 by the railway infrastructure manager with the aim to remove the local errors of the parameter $V K$ (top level of rail) as a priority, decreased significantly the values of quality numbers of respective sections, from the value 2.36 (PO4 measurement) to the value 1.31 (PO5) in the section 1.1 and from the value $1.86(\mathrm{PO} 4)$ to the value 1.59 (PO5) in the section 2.1. The tendency of results of measurements PO5, PO6 and PO7 indicates certain increase and thus quality deterioration of sections 1.1 and 2.1. In the sections 1.2 and 2.2, the quality deterioration ( $Q N$ increase) is slight only. 


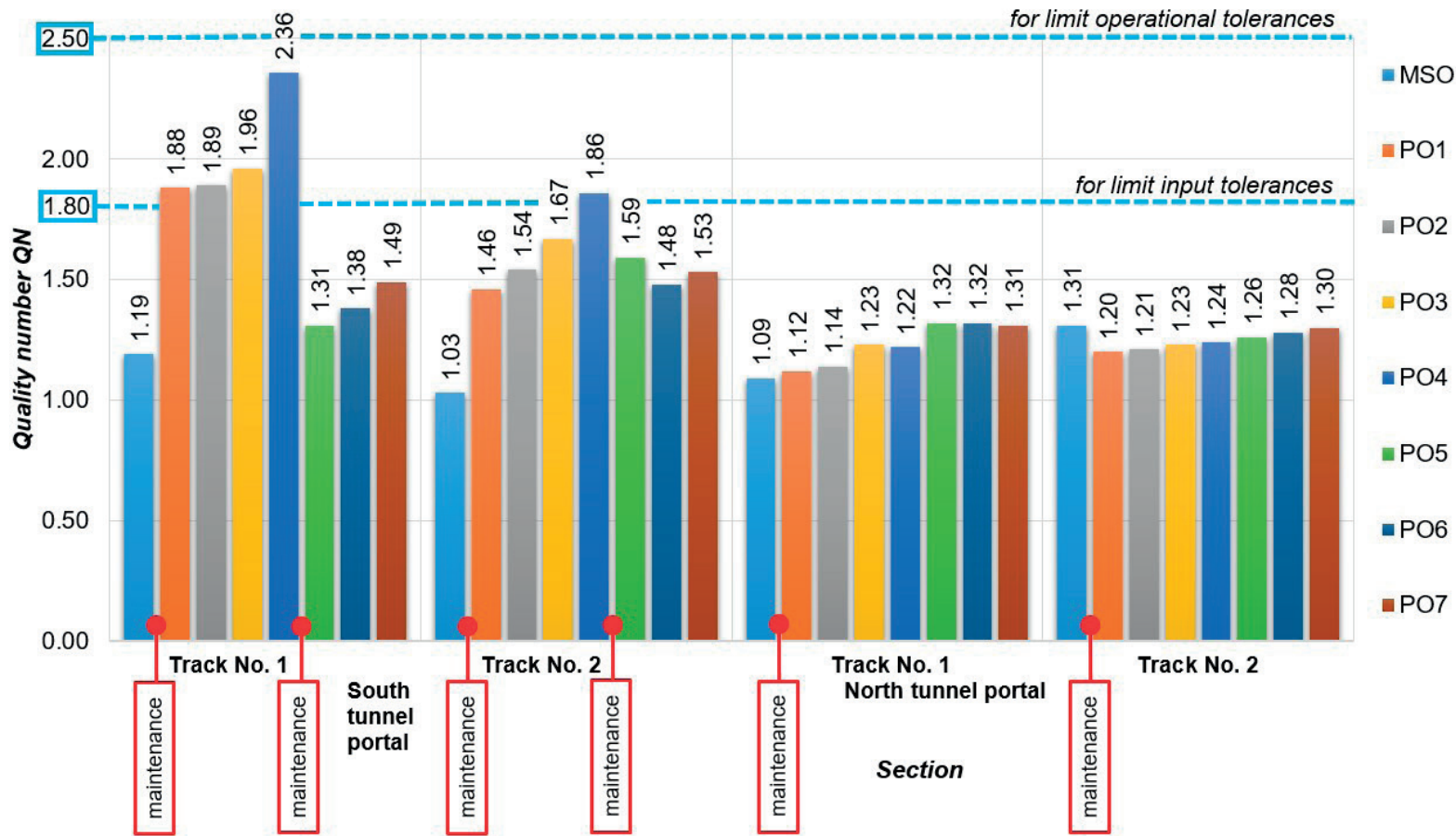

Fig. 7 Overall quality number in respective monitored sections - measurement carried out by measuring trolley KRAB ${ }^{T M}$-Light

\section{Development predictions of structural behavior}

The development prediction of structural behavior of the structure as a whole is related to transition areas from the ballastless structure to the ballasted structure as these sections are on the basis of long-term observations considered the most problematic ones. The development monitoring was carried out on the basis of data obtained by the complex continuous method by the measuring trolley KRAB ${ }^{T M}-$ Light. The quality marks reaching the highest values since the first measurement are the quality marks of the selected geometric quantity - top level of the right rail. On the basis of measured data, there were prepared graphs of tolerances of top level of the right (Fig. 8) and left (Fig. 9) rail in the transition area 1.1. The respective transition area (rail 1 of the south portal) is the most problematic one from the point of view of maintenance, error incidence and reached quality marks. However, it is necessary to mention here that after implementation of repair intervention before the fifth operational measurement, there were recorded slightly higher values of quality marks for top level of right rail in the adjacent rail (section 2.1). It is probably related to the lower quality of repair intervention implementation in the rail no. 2 .

The tolerances of the top level of the right (after calculation also of the left) rail in the transition area of the section 1.1 (Figs. 8 and 9) detect the parameter errors on the level of exceeded operational tolerance defined by values $\pm 6 \mathrm{~mm}$ in the fourth operational measurement for the right rail, or in the third and fourth operational measurement (upper limit $+6 \mathrm{~mm}$ ) and in the second and fourth operational measurement (lower limit $-6 \mathrm{~mm}$ ) for the left rail. The parameter error on the level of exceeded operational tolerance can be confirmed by errors detected by the measuring car of ZSR in individual measurements carried out within regular measurements in compliance with regulations for rail diagnostics. The completed repair of the track geometry in the transition area decreased the tolerance values but the places with limit tolerance values remained the same (contact of transition area with ballastless track and the start of the ballasteless track structure).

In the adjacent rail (section 2.1), errors of the parameters $V P, V L$ on the level of exceeded operational tolerance were not recorded, but the manager carried out a repair intervention in the same time in both rails. The repair intervention carried out in the transition area of the rail no. 2 did not improve the values of parameter tolerances in any way, only a displacement of irregularities and places with reached limit values occurred here. This can also be confirmed by the development of quality marks of considered geometric quantity - top level of the right (after calculation also the left) rail (Fig. 6), where, unlike in the rail no.1, the values of quality marks did not significantly improve after repair interventions.

From the point of view of further quality development and subsequent maintenance planning, there was observed a tendency of development of maximum tolerances of both rails (Figs. 10 and 11 ) with the prediction of reaching the tolerance of the top level of 


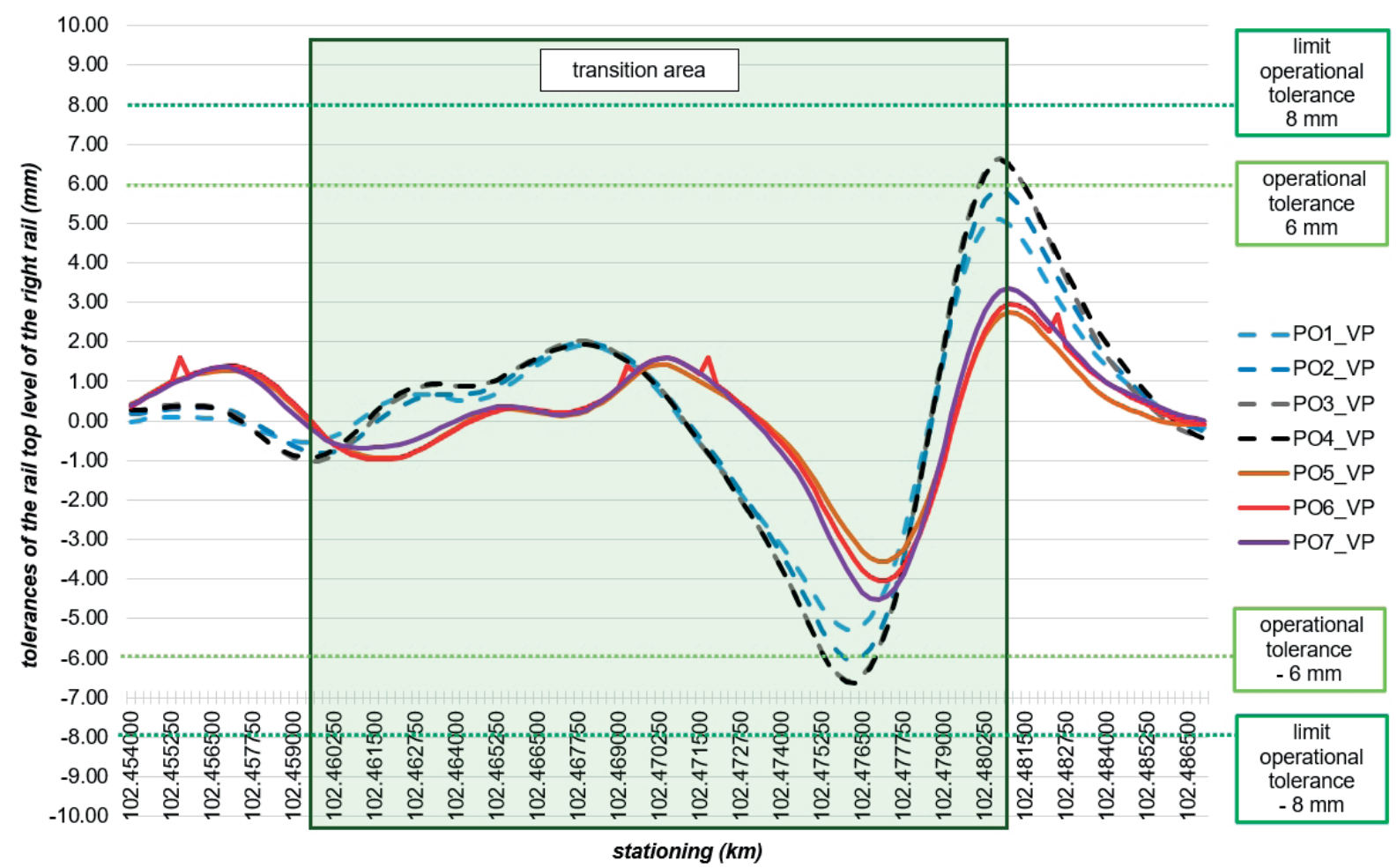

Fig. 8 Tolerance of the top level of the right rail in the transition area of the section $1.1(\mathrm{~km} 102.460500-\mathrm{km} 102.480500)$

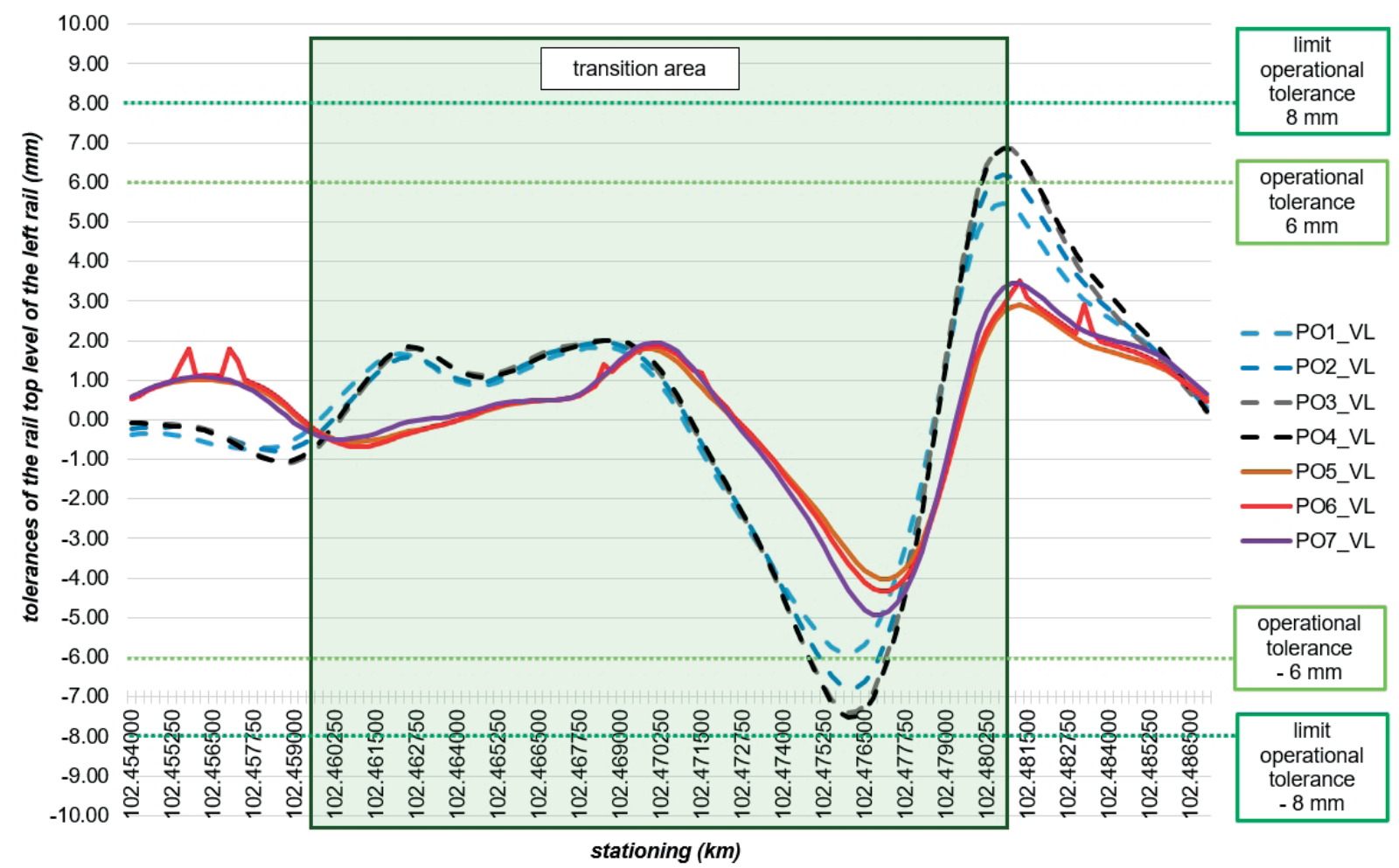

Fig. 9 Tolerance of the top level of the left rail in the transition area of the section 1.1 ( $\mathrm{km} 102.460500-\mathrm{km} 102.480500)$ 


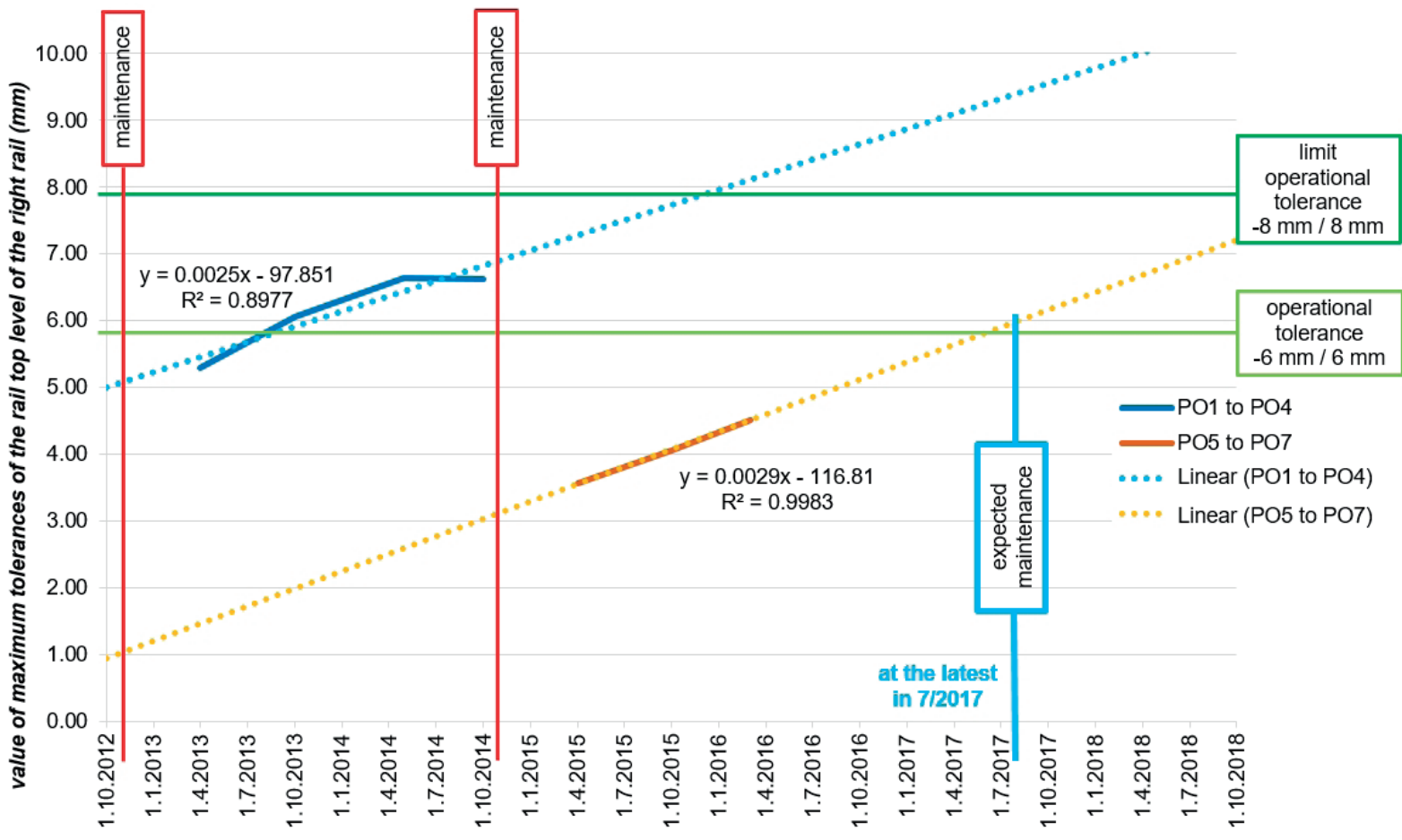

\section{measurement date}

Fig. 10 Measurements PO1 to PO7 and the developmental tendency of maximum tolerances of the right rail in the transition area of the section 1.1 and its vicinity ( $\mathrm{km} 102.454000$ - $\mathrm{km} 102.487$ 000)

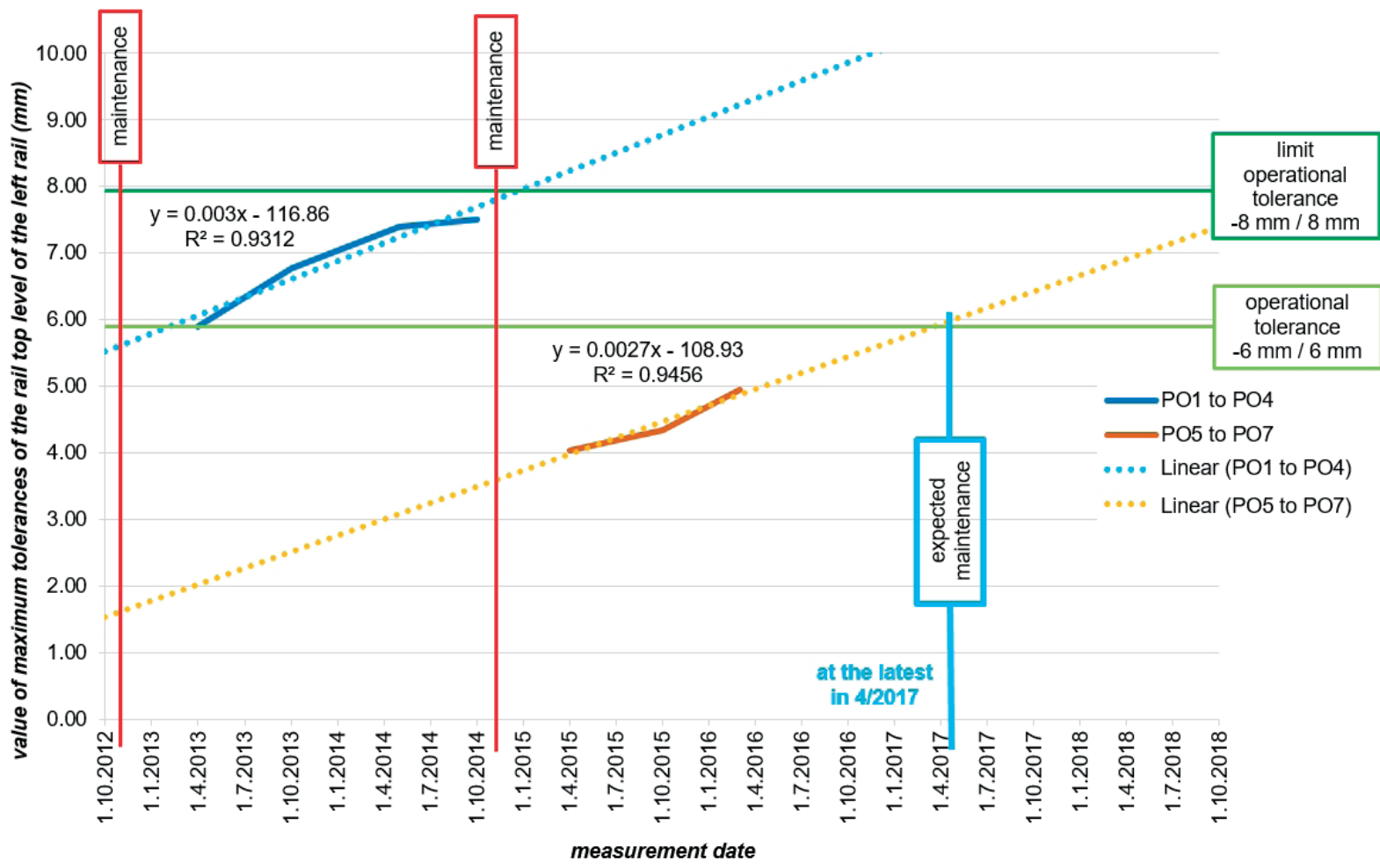

Fig. 11 Measurements PO1 to PO7 and the developmental tendency of maximum tolerances of the left rail in the transition area of the section 1.1 and its vicinity $(\mathrm{km} 102.454000-\mathrm{km} 102.487000)$ 
the right (left) rail on the level of exceeded operational tolerance. The developmental tendency shows that the absolute value of maximum tolerance of the top level of right rail will reach the level of operational tolerance at the latest in July 2017, the absolute value of the maximum tolerance of top level of left rail will reach the level of operational tolerance probably earlier - at the latest in April 2017, and these levels of exceeded operational tolerances should be detected within the second measuring campaign of the measuring car ZSR (in summer 2017). After detection of these tolerances, the infrastructure manager is supposed to plan and, as soon as possible, also to carry out the repair of track geometry in the respective section.

\section{Conclusion}

The structural parts and parameters of track geometry in the time of operation show signs of quality deterioration. Its monitoring and recording in the experimental section has been carried out for five years. At present the measurements confirm the significant quality deterioration in the transition areas of sections 1.1 and 2.1. The implementation of repair intervention after measurement $\mathrm{PO} 4$ caused certain improvement, but later there was again recorded further quality number $(Q N)$ deterioration - especially by decreasing quality of parameter $V K$ (the top level of the rail). With the exception of the parameter $R K$ (rail gauge), all the other monitored parameters of track geometry of the experimental section contribute to the quality number deterioration by their continuous degradation. The described tendency of quality decrease is expected in the further periods of operation of respective sections. The repair will be feasible only by repair interventions of track geometry carried out as soon as possible after the error detection but no later than the nearest inspection of the track state.

With regard to quality number, the sections 1.2 and 2.2 seem to be sections with slightly deteriorated quality which can be explained by the quality change of operated railway track with mixed train operation. Considering the quality development in the previous monitoring period, there is supposed a permanent decrease of construction quality, provided the operation is without any extraordinary operational events. The improvement of structural quality will be carried out by repair of track geometry as a part of the repair work plan.

\section{Acknowledgement}

The paper contains partial results of the grant project VEGA 1/0597/14 "Analysis of methods used to measure the unconventional railway track construction from the point of view of accuracy and reliability".

\section{References}

[1] IZVOLT, L., SESTAKOVA, J., SMALO, M.: Railway Engineering 2: Diagnostics, Mechanisation and Track Works Technology on Railway Track (in Slovak), EDIS : University of Zilina, 2015, ISBN 978-80-5541-169-9.

[2] IZVOLT, L., SESTAKOVA, J., SMALO, M., GOCALOVA, Z.: Monitoring of the Track Geometry Quality around the Portals of new Tunnel Construction Turecky vrch - Preliminary Result, Communications - Scientific Letters of the University of Zilina, vol. 16, No. 4, 2014, 9-20, ISSN 1335-4205.

[3] IZVOLT, L., SESTAKOVA, J., SMALO, M.: Monitoring of the Track Alignment and Track Geometry Parameters of Ballastless Track Sections and Transition Areas in Vicinity of Portals of Turecky Vrch Tunnel (in Slovak), NTT: New Railway Trends - Transport - Telematics, vol. 24, No. 3, 2016, 12-16, ISSN 1210-3942.

[4] SESTAKOVA, J., GOCALOVA, Z.: Comparison of Results of Geometrical Position of the Track Diagnostics - Spot and Continuous Measurement, Procedia Engineering [electronic source] : XXIII R-S-P seminar: Theoretical Foundation of Civil Engineering: ISSN 1877-7058 : vol. 91, 2014, online, p. 447-452 : http://ac.els-cdn.com. /S1877705814030410/1-s2.0-S1877705814030410-main. pdf?_tid=7ac2c2f8-c709-11e4 -aaf7-00000aab0f6b\&acdnat=1425980605_3c52ef455ea61af04fe1b951e4d82550.

[5] SESTAKOVA, J.: Quality of Slab Track Construction - Track Alignment Design and Track Geometry, Civil and Environmental Engineering [electronic source]: De Gruyter Open: vol. 11, No. 1, 2015, ISSN: 1336-5835, online, pp. 2-9: http://www. degruyter.com/dg/viewarticle.fullcontentlink:pdfeventlink/\$002fj\$002fcee.2015.11.issue-1\$002fcee-2015-0001\$002fcee-2015-0001. pdf?format=INT\&t:ac=j\$002fc ee.2015.11.issue-1\$002fcee-2015-0001\$002fcee-2015-0001.xml.

[6] IZVOLT, L. et al.: Monitoring of Sections of a Non-conventional Construction of the Railway Superstructure and the Transition Areas - $7^{\text {st }}$ and $8^{\text {st }}$ Stage. ZSR Modernization of Railway Track Nove Mesto nad Vahom - Puchov, km 100.500 to 159.100, part 24-32-01 Nove Mesto - Trencianske Bohuslavice (in Slovak), Zilina: KZSaTH: SvF: University of Zilina, 12/2015.

[7] STN 736360 (1999) Track Alignment Design and Track Geometry of Normal-Gauge Tracks (in Slovak), SUTN Bratislava and Amendment 1 (2002), SUTN Bratislava. 
[8] ZSR SR 103-7 (S) Measurement and Evaluation of Track Geometry by Measuring Trolley KRAB (in Slovak), GR ZSR, 2008.

[9] STN 73 6360-1 (2015) Railway Applications. Track. Part 1: Geometrical Position Arrangement of 1435 mm Gauge Railways (in Slovak), SUTN Bratislava.

[10] SMALO, M., IZVOLT, L.: Assessment of Track Quality in Trial Test Sections by Spot and Continuous Method, Communications - Scientific Letters of the University of Zilina, vol. 17, No. 4, 2015, ISSN 1335-4205. 